\title{
Dialogic Teaching Approach vis-à-vis Middle School Physics Teacher's Content Knowledge
}

\author{
Deresse Terfa Leta ${ }^{1 *}$, Mulugeta Atinafu Ayele $^{2}$, Vanessa Kind ${ }^{3}$ \\ ${ }^{1}$ Kotebe Metropolitan University, ETHIOPIA \\ ${ }^{2}$ Addis Ababa University, ETHIOPIA \\ ${ }^{3}$ Durham University, UK
}

Received 19 March 2020 - Accepted 28 October 2020

\begin{abstract}
This study aimed to explore Ethiopian middle school physics teachers' content knowledge (CK) and their implementation of Dialogic teaching (DT). A qualitative method, case study design, and purposive and convenient sampling employed in the study. Data collected using Classroom observation and Questionnaire from nine physics teachers. The comparative analysis used to compare teachers' implementation of DT. The results have indicated that the teachers' CK was limited. Every teacher has had misconceptions, and a lack of procedural knowledge in physics contents and some teachers' misconceptions were severe. None of the teachers fully implement dialogic teaching in their class. However, teachers who have training on DT and a higher level of CK relatively demonstrated DT better than teachers who have no training and have lower CK, respectively. The teacher education program recommended choosing a concurrent teacher education model, incorporating middle school physics in their curriculum for pre-service teachers, and making pre-service teachers practice dialogic teaching.
\end{abstract}

Keywords: case study, comparative analysis, content knowledge, dialogic teaching

\section{INTRODUCTION}

One of the objectives of the education and training policy of Ethiopia (Ministry of Education (MoE), 1994) is to offer primary education for all. Ethiopia is in good condition in addressing "Education For All (EFA)" and giving attention to Science and Technology. The percentage of children who had never been to school decreased by remarkable rates in Ethiopia (from 67\% in 2000 to $28 \%$ in 2011) (Barbara et al., 2003). Ethiopia increased its pre-primary Gross Enrolment Ratio (GER) considerably, from $2 \%$ in 2000 to almost $22 \%$ in 2011. The 2013/4 EFA Global Monitoring Report showed that the country also achieved large increases in its primary enrolment rates between 1999 and 2011, with its GER increasing from $50 \%$ to $106 \%$ and its Net Enrolment Rate (NER) from 37\% to 87\% (Barbara et al., 2003). Decreeing that all universities should modify their curricula so that 70 percent of student intake is to science and technologybased subjects and 30 percent to the arts and humanities (Rayner \& Ashcroft, 2011).
The education and training policy (MoE, 1994) has brought significant advantages to the citizens regarding educational equity, primary education in the mother tongue, and democratization of content in education (MoE, 2002) but, the quality of science education and especially physics, is under question. "Although many effective measures have taken to maintain quality education, there are critics who claim that, in the name of educational expansion, mediocre education is being sprinkled everywhere like "holy water" (Tebel)" (MoE, 2002). A study on five subjects (English, Mathematics, Biology, Chemistry, and Physics) at grade 8 which was done by Ethiopian National Learning Assessment (ENLA) has shown students' mean score in physics was at the bottom than other subjects (Woldetsadik, 2013). According to Semela (2010), students who joined basic science departments from the 2006/7-2008/9 academic year were low achievers in Ethiopian University Entrance Examination. In particular, those who joined physics as their carrier were the least achievers.

Research conducted by Alemu et al. (2017) shows that middle school pre-service physics teachers in Ethiopia

(c) 2021 by the authors; licensee Modestum. This article is an open access article distributed under the terms and conditions of the Creative Commons Attribution License (http://creativecommons.org/licenses/by/4.0/).

\ayantudare2008@gmail.com (*Correspondence) $\$ mulugetaayele97@gmail.com $\square$ vanessa.kind@durham.ac.uk 


\section{Contribution to the literature}

- Revealed the extent of the implementation of physics dialogic teaching approach in Ethiopia (Africa).

- Revealed the extent of middle school physics teachers' content knowledge in Ethiopia (Africa).

- Revealed how the level of content knowledge and training in dialogic teaching could promote implementing this pedagogical approach in classrooms.

scored less than grade 8 students abroad in a physics topic called sound. It means that teachers who intended to teach middle school physics achieved less than their students. During their teaching practice, some preservice middle school physics teachers were deficient in their physics CK and did not encourage students to ask questions. The classroom discourse did not elicit students' understanding and misconceptions. These all indicate how physics education was deteriorating in Ethiopia.

Two factors that affect students' achievement are the teacher's CK and classroom discourse pattern. Guerriero (2015) reviewed that CK has an impact on students' achievement, and teachers' intellectual resources affect students' achievement (Ball, 1989). A study done by Tchoshanov (2008) supports the same claim and shows that teacher knowledge and student achievement parallel each other. According to Shulman (1986), teachers' knowledge is classified into Subject matter (content knowledge (CK)), Pedagogical Knowledge (PK), and Curriculum knowledge. CK refers to the amount and organization of knowledge per se in the teacher's mind (Shulman, 1986). CK is a prerequisite for a teacher to teach. Somebody can invite something to others if he/she has. The way he/she delivers his invitation is based on the inviter's invite. So, a teacher has to have CK of his/her subject area to teach; otherwise, it is similar to inviting somebody without any invite in hand. CK has two components: conceptual and procedural knowledge (Forrester \& Chinnappan, 2010; Groth \& Bergner, 2006).

Classroom discourse is a continuum between monologue and dialogue. Monologic discourse is an instrumental approach to communication geared towards achieving the teacher's goals. In contrast, dialogic discourse is concerned with promoting communication through authentic exchanges. There is genuine concern for the talk partners' views, and effort is made to help participants share and build meaning collaboratively. Bakhtin (1981) argues that dialogue is not simply between people, but between frames, people use to categorize experiences (Lyle, 2008). A study has been done by Ugwuadu (2013) on two senior secondary biology students in Nigeria. The study has shown that democratic/dialogic discourse patterns enhanced students' achievement in biology more than monologic discourse patterns.

Somebody can talk about what he knows. Our thought can be reflected and well-structured through talk. Psychological evidence, supported by neuroscience, demonstrates the intimate and necessary relationship between language and thought, and the power of spoken language to enable, support, and enhance children's cognitive development (Alexander, 2008). Alexander (2008) uses the term "dialogic teaching" to describe what happens when teachers and pupils work together to build on their own and each other's knowledge and ideas to develop coherent thinking (Lyle, 2008). DT reflects that knowledge and understanding come from testing evidence, analyzing ideas, and exploring values, rather than unquestioningly accepting somebody else's certainties.

[DT] explores the learner's thought processes. It treats students' contributions, and especially their answers to the teacher's questions, as stages in an ongoing cognitive quest rather than as terminal points. And it nurtures the student's engagement, confidence, independence and responsibility (Alexander, 2008).

Teacher's Knowledge Domains affect students' achievement. Better CK of teachers implies higher student achievement, which indicates that CK has direct and indirect implications on Student achievement. Also, classroom discourse pattern has impacts on students' understanding and their achievement. Dialogue plays a mediational role in helping children reach higher cognitive development levels at an earlier age (Lyle, 2008). DT explores the learner's thought processes; treats students' contributions; and nurtures the student's engagement, confidence, independence, and responsibility (Alexander, 2006). Dialogic and participatory pedagogy complement and sustain achievement (Deakin et al., 2004). Understanding this effect, governmental and non-governmental organizations have been giving teachers training to develop their Knowledge Domain and classroom discourse pattern.

There are numerous studies about physics teachers' Knowledge Domains and their classroom discourse in other countries. There is no research conducted on middle school physics Teachers' content knowledge (CK) and DT implementation concerning grade 7 and 8 physics topics to my knowledge in Ethiopia. By exploring middle school (grade 7 and 8) physics education, Teacher's CK related to grade 7 and grade 8 physics topics, the implementation of DT in physics classroom and comparing the implementation of DT 
concerning training in DT and teachers $\mathrm{CK}$, we can better understand the difficulties in middle school (grade 7 and 8) physics education.

This study aimed to explore Addis Ababa, Ethiopian middle school physics teachers' content knowledge (CK), and implementation of DT in their classes. In line with the purpose of the study, the following questions addressed:

1. How does DT manifest in the middle school physics classroom?

2. How is the middle school physics teachers' CK on grade 7 and 8 physics topics: Newton's law of motion and graphical representation of motion?

3. How does the level of content knowledge and training in dialogic teaching could potentially promote the implementation of DT in the physics classroom?

This study is significant in:

- contributing to Education and training policy of Ethiopia to enhance the quality of Physics Education;

- providing insights into the middle school physics teachers' content knowledge and promoting the implementation of DT in the physics classroom;

- Informing curriculum development and evaluation department that middle school textbooks revisited; and

- contributing to literature as no studies have identified how content knowledge and training in dialogic teaching promotes the implementation of dialogic teaching in physics class.

\section{LITERATURE REVIEW}

\section{Conception of Motion and Force}

Aristotle categorized motion into:

- Natural motion, such as falling, came from objects' tendency to go to their "natural" place, on the ground, and come to rest.

- A voluntary motion was the type of motion exhibited by animals, which moved because they chose to.

- Forced motion occurred when an object was acted on by some other object that made it move (Crowell, 2001).

Aristotle's view of motion is "motion requires force," which can be summarized as $\mathrm{F}=\mathrm{mv}$. That implied, if there is no force on an object, the object has no velocity. Aristotelian sees force as an internal property of objects, where objects create, destroy, or alter their internal force to get to rest in the objects' sphere of choice. This theory of internal force has been given the title impetus. However, violent motion is to do with two objects' interactions, mainly an animal or human creating an unnatural state for the object. This conception implies that only living things can exert (non-natural) forces (Crowell, 2001).

Crowell (2003) notes: "Although this basic theory appears to be a reasonable outcome of experience with real-world motion, it is strikingly inconsistent with the fundamental principles of classical physics. The naive theory is remarkably similar to a pre-Newtonian physical theory popular in the 14th through 16th centuries."

After Aristotle, Newton defines his three laws of motion, different from Aristotle's long-standing view (Lark, 2007). The first law summarized as: objects keep moving or remain at rest unless an external force is applied to it, which contradicts Aristotle's view that forces cause motion and objects tend towards rest. Newton's second law ( $\mathrm{F}=\mathrm{ma})$ differs mathematically as well as conceptually from the previous, $\mathrm{F}=\mathrm{mv}$. Motion is not created by force but changed by the application of a force. Newton's third law: for every action, there is equal and opposite reaction force, in contrast to Aristotle's view, where force is mostly an internal entity. The goal of physics classes is to shift physics students from the more intuitive Aristotelian view to the more scientifically accepted Newtonian view (Lark, 2007).

Hestenes et al. (1992) classified the Newtonian force concept into kinematics, first law, second law, superposition principle, and kinds of force. The two main kinds (types) of force (contact and non-contact forces) are classified into solid contact, fluid contact, and gravitation. The force concept inventory (FCI) data has detected misconceptions in motion and force. It confirms the similarity of misconceptions with other educational researchers. Most misconceptions identified are similar to the Aristotelian conception of force. Misconceptions probed by Hestenes et al. (1992) were classified as kinematics, impetus, Active force, action/reaction pairs, Concatenation of Influences, and other influences on motion (Hestenes et al., 1992).

Studies show that students at college and high school level (Brown, 1989; Clement, 1982; Thornton et al., 1998) have misconceptions consistent with Aristotelian mechanics. A study done by Brown (1989) indicated that high school students enter physics classes with preconceptions in the area of Newton's third law. The preconceptions may result from students' general naive view of force as a property of single objects rather than a relation between objects (Brown, 1989). Almost all misconceptions identified by different scholars were similar to the misconceptions identified by Hestenes et al. (1992).

Even though students' CK was studied at different school levels, there is no study on in-service middle school physics teachers' CK, particularly Newton's law 


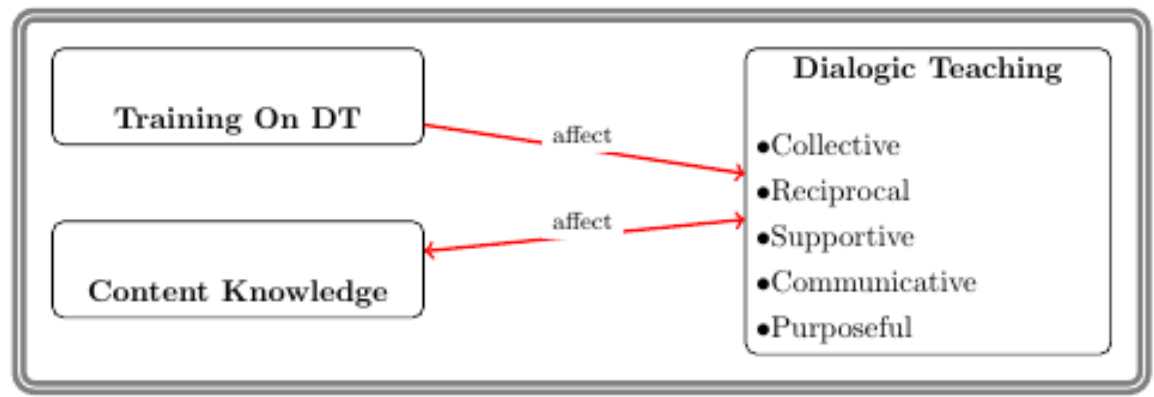

Figure 1. Conceptual framework for the study

of motion and graphical representation of motion. That was one primary aim of this study.

\section{Principles of Dialogic Teaching (DT)}

Talk by a teacher and students stimulates and extends students' thinking and promotes students' learning, which can be done when teachers engage in dialogic teaching practices. Students are listened, probed, challenged, and their understanding is scaffolded. On the other hand, students are engaged in dialogic exchanges when they share ideas, listen to each other, and challenge alternative ideas (Gillies, 2016).

Dialogic teaching and learning afford students greater authorship, meaning, and more equitable opportunities to learn (Kumpulainen et al., 2017; Reznitskaya, 2012). The dialogic teaching approach in science education provides students with opportunities to negotiate their everyday and scientific reasoning, manage alternative viewpoints, appropriate the cultural norms and discourses of the discipline, and build a positive attitude toward science (Reznitskaya, 2012).

DT is an approach that uses the power of talk in teaching and learning. DT supports any teaching methods the teachers use in their class in any context, which indicates that DT is not a single teaching method, and it supports different teaching methods. It is applied/used in any teaching method. Any method: lecture, demonstration, discussion, question and answering, and others can be enhanced by a quality talk between a teacher and students.

Alexander's DT includes five features. If classroom talk does not meet the five conditions, it is not dialogic (Alexander, 2008). In this research, these components were looked at. The five principles of Alexander, (2008) DT are:

- collective: teachers and children address learning tasks together, whether as a group or as a class;

- reciprocal: teachers and children listen to each other, share ideas and consider alternative viewpoints;

- supportive: children articulate their ideas freely, without fear of embarrassment over 'wrong' answers; and they help each other to reach common understandings;
- cumulative: teachers and children build on their own and each other's ideas and chain them into coherent lines of thinking and inquiry

- purposeful: teachers plan and steer classroom talk with specific educational goals in view (Alexander, 2008).

Ethiopia's education and training policy recommend active learning, student-centered, and problem-solving approaches associated with constructivism. However, in class, teachers experience the behaviorist approach, and the textbooks initiate for teacher-centered approach. Therefore, this study will explore how teachers experience DT, emphasizing social constructivism learning theories, in their classroom.

\section{Conceptual Framework}

The study's conceptual framework was developed, and the framework has been used to guide and inform the research. This study's central phenomena were the Teachers' CK and their implementation of DT in the classroom. The conceptual framework is shown in Figure 1. The framework includes teachers' CK, principles of DT, and training on DT. The framework was used as an organizing framework for the study, which is: conceptualization, data collection and tools, and the analysis of data. In the framework, since DT harnesses the power of talk in the teaching and learning process, the researchers considered how teachers' CK and their implementation of DT affect each other, and how training affects DT implementation.

The conceptual framework has strength in showing a clear direction, how training in DT and teacher's CK affect the implementation of DT, and has a limitation in discriminating which components of CK (conceptual and procedural) affect DT more.

\section{METHODS}

\section{Research Design}

The study employed a qualitative research method and an exploratory case study design. Approval was obtained from the Department of Science and Mathematics Education and permeated by Addis Ababa Education Bureau. After the research's permission, the 
questionnaire developed, participants invited, and the participant complete and signed a consent form.

The questionnaire was developed by the researcher and validated by professionals (comments of colleagues and supervisors). Each item of the questionnaire comprises both close-ended questions and open-ended questions except one which comprises only open-ended questions. Nine participants were invited from inservice middle school teachers from four schools in Addis Ababa, Ethiopia. The schools were chosen based on their proximity to the researcher's working place, and teachers who have at least three years of working experience were selected from each school when they agreed to work with the researcher. Therefore, these make the sampling technique purposive and convenient. The participants' teaching experience ranges from 3 years to 12 and their ages from 25 to 33 . Five teachers are female, and the rests are male. Except for two teachers, all teachers have a first degree in physics. The two teachers were attending their degree programs. Four participants have given a day training in DT.

After the questionnaire's validation and the participants agreed and signed the consent form, each participant filled the questionnaire. Each participant class was observed twice while they taught on subcontents in Newton's law and the graphical representation of motion. After classes, the teachers have been asked for extra explanations where misconceptions were observed. From the teachers' questionnaire and classroom observation responses, the level of implementation of dialogic teaching was ranked into No, partial, and full, and teachers' CK was ranked into very poor, poor, average, good, and very good.

\section{Data Collection Instruments}

The study used two instruments: video-based classroom observation and teachers' questionnaire. The researchers developed the questionnaire and validated by professionals (supervisors and colleagues), but not pilot tested. Video-based classroom observations have been held while the teachers have been teaching. Doring observation, two video cameras were used. One camera has been recording the whole classroom activities, and the second has been recording the teacher's activities and utterance. Both videos were used to explore how physics teachers' CK and DT are manifested in the physics classroom. Classroom observation is the best way to analyze what is going on in the real class. During observations, there was no intervention by the observer. Therefore, the observations were naturalistic. The behavior of the teacher has indeed been influenced because of the cameras in the classroom. The researchers overcame the problem through repeated classroom observation, and the teacher forgets the camera's existence through time. Two to three video observations have been done in each teacher's class. The first observation was used to accustom the teacher and the students with the cameras and the observer. The questionnaire helps measure the specific characteristics or opinions of the respondents. The questionnaire helps to dig out what is latent about the teacher during classroom observations. The questionnaire was a selfcompletion, and it has ten items for teachers' CK.

The trustworthiness of the study was ensured with multiple procedures. Two instruments were used, and the supervisors checked the data analysis to triangulate the data. A thick description of the study was given to ensure transferability. An inquiry audit was used by involving colleagues (professionals) in review and examine the research process and the data analysis to establish dependability.

\section{Data Analysis}

Data were examined, classified, and organized to address the primary purpose of the study. These were done in the classroom observations and questionnaires. The analysis explored the teachers' $\mathrm{CK}$ and the implementation of DT in the physics classrooms based on Alexander's (2008) principles of DT. In this analysis, NVivo software was employed in scanning themes and $\mathrm{R}$ in analyzing frequency and plotting bar charts.

In the analysis of classroom video-based observation, the video-based observation was transcribed verbatim. The data were sorted into features of dialogic teaching: collective, reciprocal, supportive, cumulative, and purposeful and teachers' content knowledge: conceptual and procedural. In the questionnaires' analysis, the data was sorted into misconceptions and correct conceptions that the teachers hold. Since each questionnaire's item starts with close-ended questions, it can help the researchers judge the respondents' response correct or incorrect and ends with open-ended questions, which explores the respondents' understanding of the physics concept.

\section{Ethical Considerations}

This research works on teachers. Therefore, the researcher respects the right of his/her respondents; minimizes or avoids any risk or what will make the respondent disadvantageous; and pays an incentive to compensate the time lost by the respondent. Permission has been sought from the Department of Science and Mathematics Education, City education bureau, and Schools to access teachers and schools. After getting permissions from these respective offices, the researchers have provided the respondents with the precise nature and scope of the research: the aims, design, methods, and procedures to be used, nature and size of samples, the activities to be observed, subjects to be interviewed, time involved, arrangements to guarantee confidentiality, how the findings would be disseminated, a timetable and whether assistance would be required in the organization and administration of the 

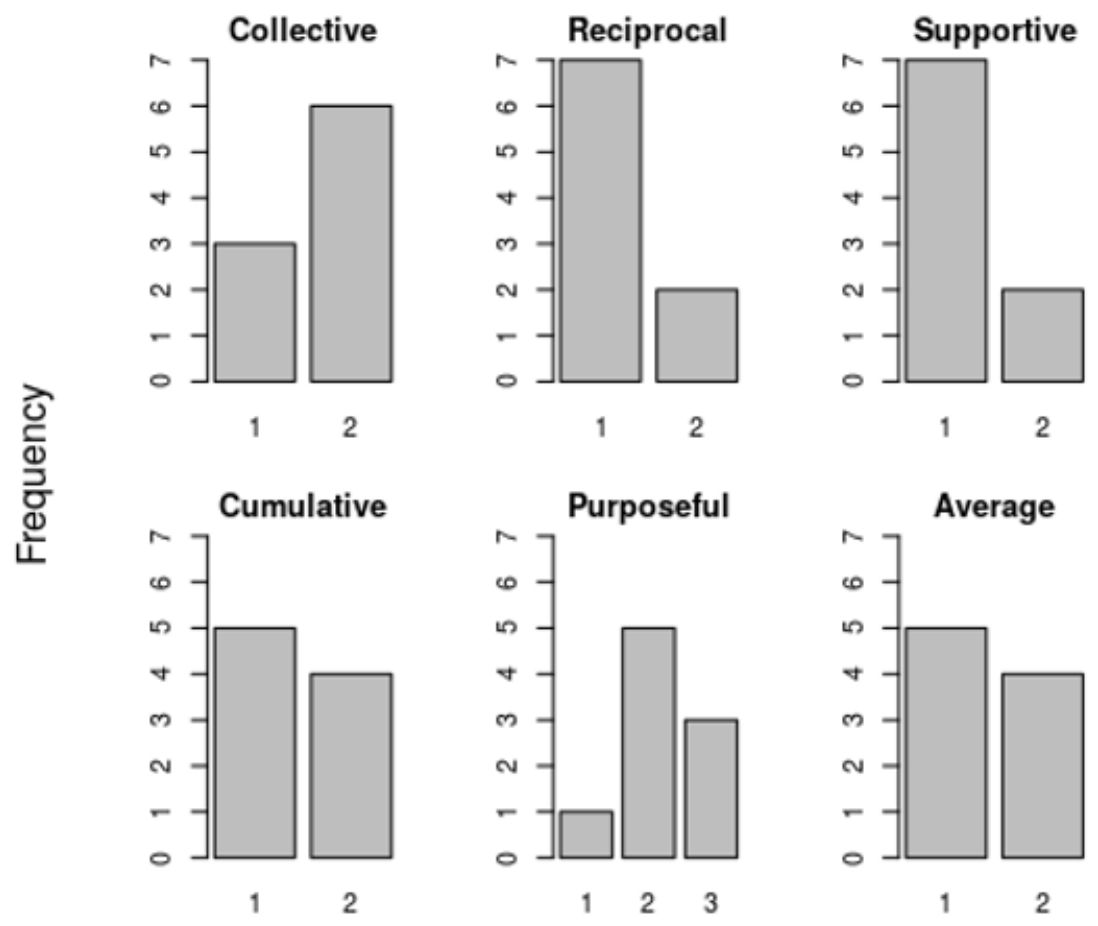

DT: 1=No, 2=Partial, 3=Full

Figure 2. Implementation of DT in Physics class

research. Only those who agreed to participate in the study were included.

Participants (middle school physics teachers) have been invited to be included in the study and informed before the data collection. They have given the right to refuse to take part or withdraw once research had begun. Briefing sessions have been held with the participants to ensure that they knew what will be involved in the research, be fully aware of the research's purpose, and understand their rights. They have completed and signed a consent form to indicate whether they would or would not participate.

Information obtained from the participants has been used as agreed during informed consent. Respondents would not be identified or presented in an identifiable form. Their anonymity has been preserved at all times by ensuring that no names are used in the written report. Teachers have given pseudonyms so that the researcher was the only one who knew how to identify them. Data were kept safe and confidential. Participants have been protected from any kind of harm, physical or psychological.

\section{RESULTS}

A summary of the results of each research question was given as follows.

\section{Research Question 1}

\section{How does DT manifest in the middle school physics classroom?}

Teachers' implementation of DT was analyzed for its five features, and the implementation was ranked "No," "Partial," and "Full." As shown in the bar graph (Figure 2), every teacher could not demonstrate all DT features fully except three teachers who showed only the purposeful feature. There was variation among teachers in implementing every feature of DT. From five features of DT, a purposeful feature was better demonstrated. Every teacher except two addressed the contents in the topic and planned and structured with specified learning goals. Few teachers have been addressing contents out of the topics and beyond the level of the students.

Most teachers partially demonstrated the collective feature of DT. In these teachers' classes, sometimes students have been participating in the lesson activities, and the teachers also use recitation and/or instructional teaching talk repertoires. In a few teachers' classes, the repertoires of teaching talk were all recitation and/or instructional. The teachers' classes were teachercentered.

The most difficult features of DT for the teachers to implement in their class were reciprocal and cumulative features. In every class, there were no contesting ideas on which students agreed or refute. Moreover, students were not encouraged to reflect on their ideas, and once 


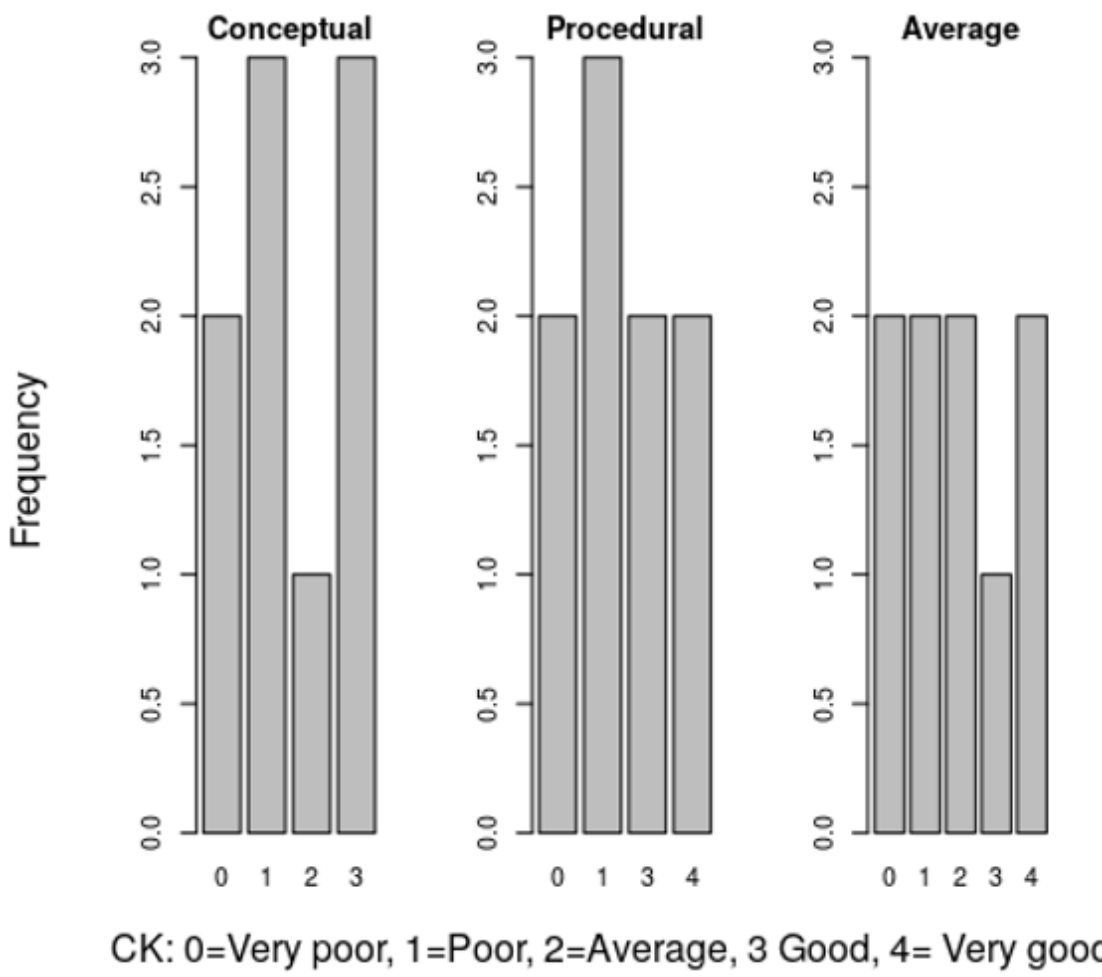

Figure 3. CK as observed in Classes

the teachers got the correct answer or idea from the students, they did not look for other students' ideas. The cumulative features of DT were partially demonstrated in some teachers' classes, and in other teachers' classes, almost there were no supportive and cumulative features.

\section{Research Question 2}

\section{How is the middle school physics teachers' CK associated with grade 7 and 8 physics topics?}

Figure 3 shows a bar graph of teachers' CK observed in teachers' classes. The bar graph depicts that most teachers' conceptual and procedural knowledge was less than average, and every teacher has misconceptions in Newtons' laws of motion and graphical representation of motion. The extent of misconceptions varies from teacher to teacher, and some teachers were not recommendable to teach at this level.

Areas of teachers' misconceptions were inertia, the relationship between velocity and acceleration, computing average velocity, and average acceleration from a graph. Every teacher has misconceptions in computing average velocity and average acceleration from the graph.

A teacher relates inertia with her thinking; others argue that a body has inertia if it is at rest and has no inertia if it is in motion. Also, some teachers conceptualized inertia is the cause for a body to stop its motion, or if there is no force applied to the body, it stops its motion.
In computing average velocity from tabular data, the teachers forgot that average velocity and average acceleration are the total displacement ratio to the total time elapsed, and change in velocity ratio to the total time elapsed, respectively (Serway et al., 2008). To compute average velocity, the teachers divide each position with each corresponding time. To compute average acceleration, they divided each velocity with each corresponding time. Some teachers relate velocity and acceleration as if they had a direct relation.

Some teachers thought that Newton's third law did not work for every object. They argue that because of the Earth's magnetic force, the magnitude of gravitational force on an object around the Earth's surface is greater than the reaction force the object exerts on the Earth. Some teachers thought that if an object makes another object accelerated, then the object exerts greater force than the one which is made accelerated. Also, a teacher argues that the action force is negative to the reaction force and the reaction force is positive to the action force. There was also a teacher who conceptualized the effects of force as Newton's laws of motion.

Table 1 shows responses to the ten-item questionnaire. Nine of them start with close-ended questions. From these nine questions, the teachers answered $14-67 \%$ correct. From the explanation the teachers have given, their misconceptions range from 30 $78 \%$ of the ten questions. Some teachers got the correct answer for the closed-ended questions, but they had misconceptions about the idea in their explanation. 
Table 1. Middle school teachers' CK and misconception from Questionnaire

\begin{tabular}{|c|c|c|c|c|c|c|c|c|c|c|c|}
\hline \multirow[b]{2}{*}{ In $\%$} & \multicolumn{6}{|c|}{ Content Knowledge \% } & \multicolumn{5}{|c|}{ Misconception \% } \\
\hline & 14 & 22 & 33 & 44 & 56 & 67 & 30 & 50 & 60 & 67 & 78 \\
\hline Frequency & 1 & 1 & 1 & 2 & 2 & 2 & 2 & 2 & 3 & 1 & 1 \\
\hline
\end{tabular}
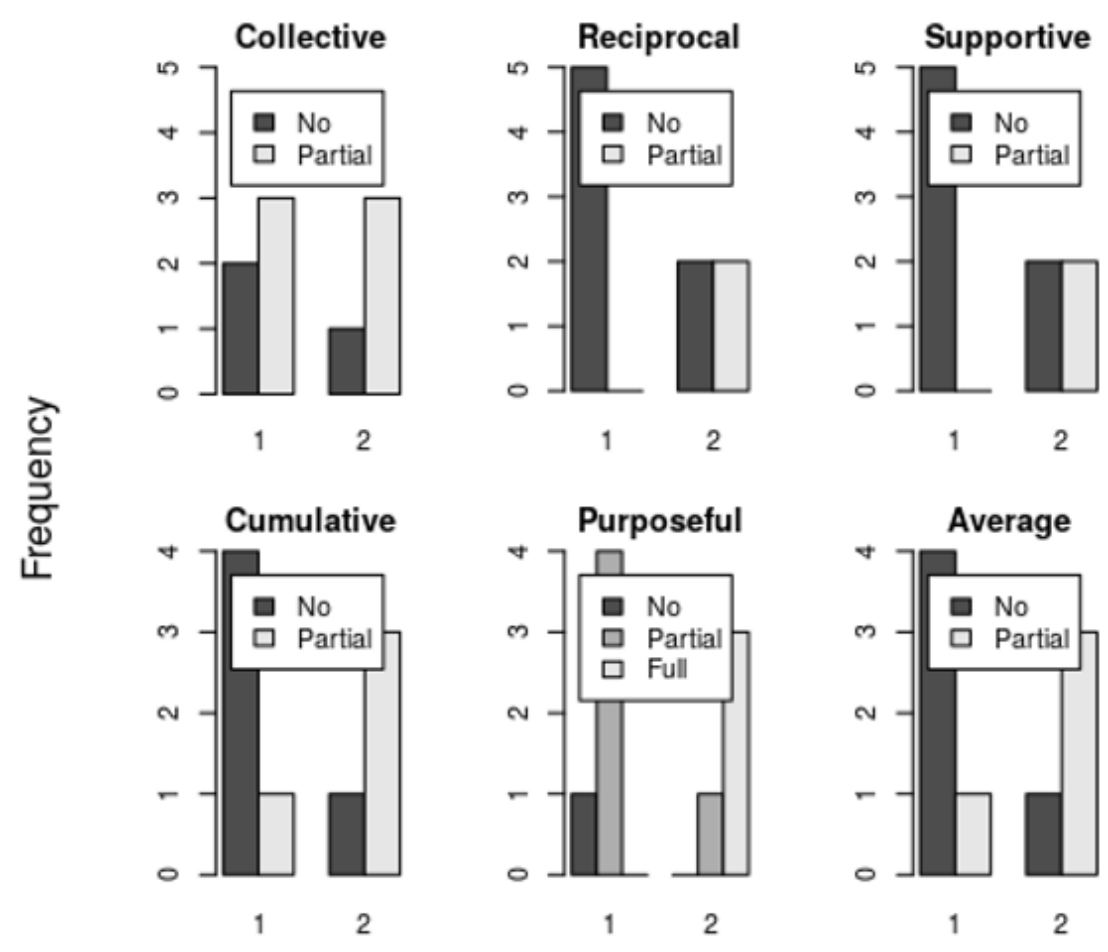

Training on DT: 1=Untralned, $2=$ Trained

Figure 4. Comparison of DT with respect to Training on DT

\section{Research Question 3}

\section{How does training on DT and teachers' Knowledge Domains' affect middle school physics teachers' implementation of DT?}

The bar graph shown in Figure 4 shows teachers' implementation of each feature of DT in their classes with respect to Training on DT. More proportion of trained teachers have demonstrated all features of DT more than untrained teachers.

Even though trained teachers have betterdemonstrated DT features, according to Alexander (2008), both trained and untrained groups did not demonstrate DT in their class. Alexander (2008) argues that unless a classroom talk meets DT's five principles, it is not dialogic. Except for the purposeful feature of DT all features were not fully demonstrated in every class.

The bar graph in Figure 5 compares the implementation of DT with respect to each teacher's CK. The bar graph shows that except for a collective feature, in all DT features, more proportion of teachers whose CK were greater than $50 \%$ were better demonstrated than teachers whose $\mathrm{CK}$ were less than $50 \%$. The four features of DT are positively affected by teachers' CK. In DT's collective feature, the two groups $(\mathrm{CK} \geq 50 \%$ and $<50$
$\%)$ have demonstrated equal proportions. The average of DT was consistent with each feature.

\section{DISCUSSION}

\section{Dialogic Teaching}

The bar graph in Figure 2 shows that fulfilling the five principles of DT was difficult for the teachers. Therefore, the teachers could not demonstrate dialogic teaching fully in their classes.

\section{Collective Feature}

In a few teachers' classes, especially from the trained group, there was good students' participation. Teachers mainly led the students' participation. Students' contribution to addressing the learning task was minimal; on the contrary, most teachers' classes, mostly from the untrained group, students' participation was not observed. Teachers pose questions, and some students respond to the question, or the teachers themselves answer the posed question. Therefore, the classes were more off teacher-centered.

In general, in most classes, students' ideas were not reflected; rather, teachers' recitation and instructional 

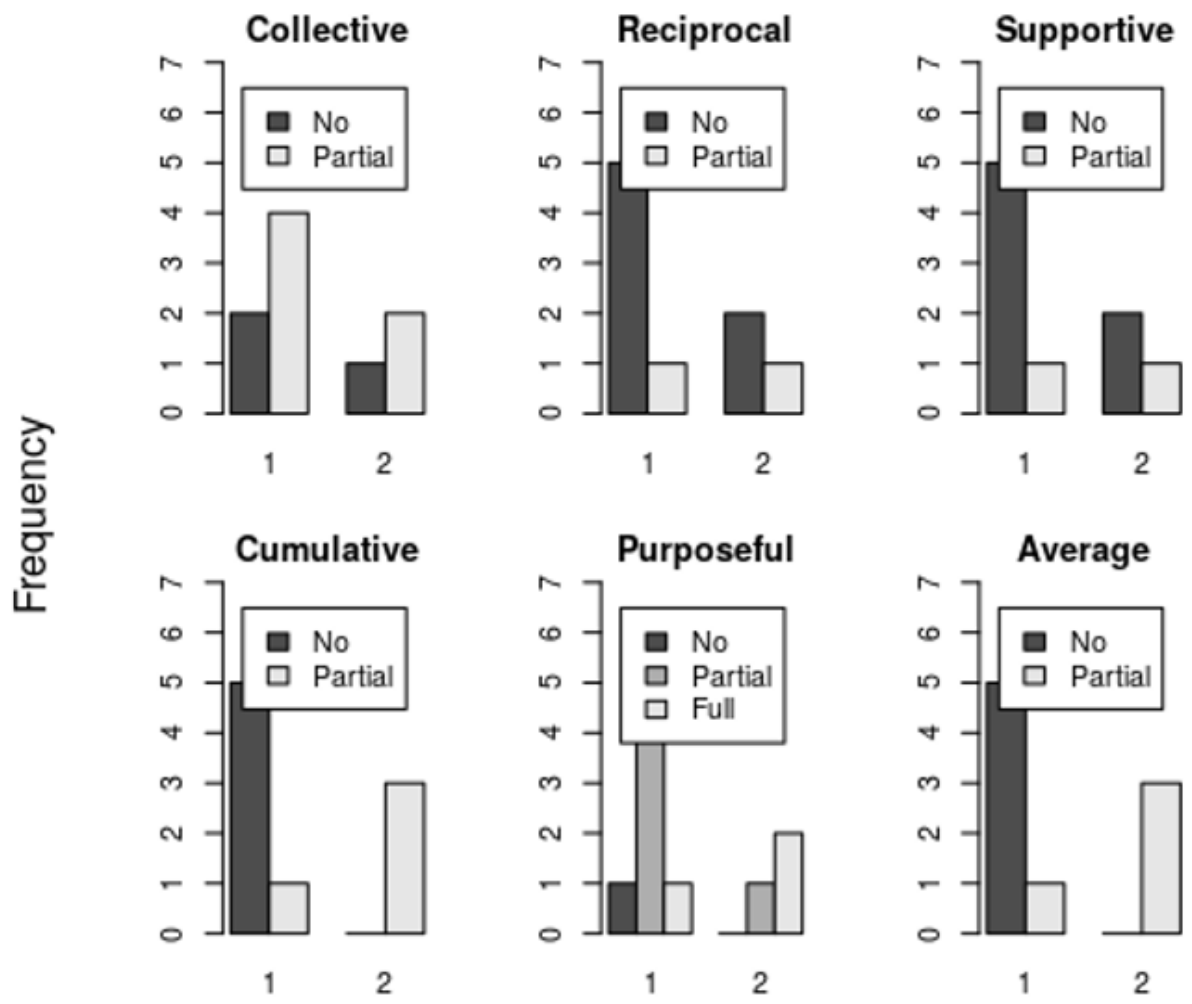

CK: $1=<50 \%$ and $2=\geq 50 \%$

Figure 5. Comparison of implementation of DT with respect to CK

repertoire were dominant. Except in a few teachers' classes from a trained group, students were not encouraged to reflect their idea. Therefore, the collective feature of DT was superficial in a few teacher's classes, and in other teachers' classes, it was absent. The teachers were dominant in their class, and students have no responsibility. Students' explanations, narration, and questions were almost absent.

From comparative analysis, based on training on DT, the result has indicated that collective features of DT are partially demonstrated in physics teachers' classes who have training on DT. On the contrary, there was no difference in implementing DT between less and high achiever teachers in their content Knowledge, which indicates that DT's collective feature does not require the CK of the teacher. It needs the involvement of both teachers and students in the activity.

\section{Reciprocal}

Even though a few teachers from the trained group look for alternative ideas and extend the discussion, most teachers from both trained and untrained groups have been looking for a correct answer. The teachers did not relate students' answers to each other. Most teachers did not encourage students to support or refute other students' ideas; instead, they ask other questions or continue their discussion without students coming to a common understanding. The teachers summarize the idea authoritatively. There were no contesting ideas reflected among students.

In Dialogic class, "the teacher does not miss opportunities to make visible the connections among student ideas and prompt students to relate their ideas to what's been said by others. He or she often attributes student ideas and questions to specific speakers." (Reznitskaya, 2012). Therefore, the classrooms lack DT's reciprocal feature in every teacher's class except two teachers who demonstrate partially. More proportion of teachers who have training on DT and who have achieved $\geq 50 \%$ in their CK have partially better demonstrated than teachers who have no training and who achieved $<50 \%$, which indicates that training in DT and teachers' CK can promote the implementation of the reciprocal feature of DT. This feature needs teachers to raise questions and give feedback on the students' ideas and direct them.

\section{Supportive}

Even though students have no fear of embarrassment, in their wrong answer, some teachers discourage students in their classes. For example, while a student answered a question, and the student left the day's topic, the teacher command "stop," which discourages students from engaging in activities. During group discussions, few teachers were moving among students to steer the discussion, have been giving a chance to students who were reluctant to answer 
questions because of their shyness. Most teachers' especially from the untrained group, feedbacks were non-informative and non-discriminating.

Some teachers ask numerous questions at a time without sufficient waiting time, which does not help students to think aloud, and it invites memorization. There were teachers from the untrained group who speaks to the blackboard while writing on the board, which made students not see the teacher's body language, and instead of following the teachers, the students were tied to note-taking. There were students in some classes who were idle during problem-solving. In most classes, students did not ask questions and provided explanations, and they are not encouraged to do so. Therefore, most classes lack the supportive feature of DT.

DT's supportive feature was more demonstrated in more teachers who have training in DT than those who have no training. More teachers who achieved $\geq 50 \%$ in their CK partially demonstrated DT in their classes than those who achieved $<50 \%$ ).

\section{Cumulative}

Some teachers raise unstructured and ambiguous questions and/or ask numerous questions at a time. These questions prevent students' participation and could not help students to build their knowledge on their own and others. The questions were not provoking thoughtful answers and did not help students construct their knowledge based on what they know. Students' answers did not provoke further questions. Therefore, teachers' questions and students' answers did not enhance DT's cumulative feature in the classes.

All teachers, especially untrained teachers, ask for a lower-level cognitive domain and close-ended questions, which does not probe the students' understanding. Teachers look for a correct answer, and once a student gives the correct answer, the teacher did not probe for other ideas or comments. The teachers could not work with students' answers to inspire further exploration. The teachers use short or ambiguous feedbacks. The feedbacks were not informative and discriminating. The feedbacks did not invite students to develop their answers further (Reznitskaya, 2012). On the contrary, many teachers from the trained group ask questions that can elicit students' understanding based on student's responses and help students build their understanding of their prior knowledge.

After the whole class or group discussion, most teachers did not chain students' ideas and ended their discussion without developing a common understanding. Instead, the teacher tells the students the fact as a summary. Therefore, DT's cumulative feature was not well-demonstrated in teachers' classes, which indicates that most teachers have an authoritative view of teaching. Cumulative features of DT partially demonstrated in more proportion in teachers' classes who have training in DT and who have achieved $\geq 50 \%$ in their CK than teachers who have no training and who achieved $<50 \%$, respectively.

\section{Purposeful}

Every teacher, except three teachers (one from the trained group and two from the untrained group), addressed the topics' contents. The three teachers have been raising contents out of the topic and beyond the students' level. During group discussion, to maintain the topic of discussion, most teachers were steering the class or groups very well, and few teachers could not follow their students' activities very well while discussing issues out of the topic. Some teachers allotted more than needed time for classroom discussion. As a result, some students were idle and bored as time goes on.

There were two teachers from the trained group, who were well-planned and used their time purposefully. Even though the duration of time was significantly different, every teacher has been giving notes on the blackboards. Three teachers (one from trained and two from untrained) have wasted most of their time giving notes, which made them not accomplish the contents they were intended to teach. Therefore, from all features of DT, this feature is better demonstrated in teachers' classes. The purposeful feature of dialogic teaching was fully demonstrated in teachers' classes who have training in DT than those with no training and in more proportion of teacher's class who achieved $\geq 50 \%$ than $<$ $50 \%$ in their CK.

In general, teachers who have trained on DT and who achieved $\geq 50 \%$ in their content knowledge have demonstrated features of DT in their classes than teachers who have no training on DT and who achieved $<50 \%$ in their CK, respectively.

\section{Content Knowledge}

As it is revealed, in both classroom observation and response to the questionnaire, there were teachers with misconceptions and a lack of procedural knowledge. These misconceptions and lack of procedural knowledge were severe in some teachers. Most misconceptions were similar to misconceptions identified by Hestenes et al. (1992). The result from both classroom observation and response to the questionnaire were consistent. Like Talbert (1993), most teachers' CK was fragmented, and were forced to teach algorithms and facts they remember. As a result, two teachers are not recommended to teach at this level.

Significant areas of misconceptions observed were inertia, average velocity, average acceleration, the relation between velocity and acceleration, interpreting graph, Newton's second law, weight, and gravitational acceleration, dividing a number by zero, and Newton's third law. The teachers' misconceptions were similar to 
students' misconceptions identified by Hestenes et al. (1992); Brown (1989); Clement (1982); Thijs (1992); Thornton at al. (1998) and also consistent with Aristotelian mechanics.

Like Hestenes et al. (1992), active force, Ethiopian middle school physics teachers have misconceptions in average velocity and average acceleration, and their relation to force. They conceptualized, velocity is proportional to force, and the direction of an object's velocity is always in the same direction of force and acceleration, which is consistent with Poutot et al. (2015) finding on high school students. Some teachers conceptualized the number over zero is zero. Also, some teachers could not differentiate the gravitational force (weight) and gravitational acceleration. They argue the weight of a body is $9.8 \mathrm{~m} / \mathrm{s}^{2}$.

They conceptualized Newton's third law does not work for everybody, consistent with Fadaei et al. (2015) and Hestenes et al. (1992), which says large mass implies large force. Every teacher has no understanding why an object around the Earth's surface accelerates toward the Earth while the Earth does not accelerate toward the object. In general, teachers' misconceptions were severe in some teachers to the extent they may lead students to misconceptions about the contents they were teaching.

\section{CONCLUSION}

The study revealed that Ethiopian middle school physics teachers could not fully demonstrate all Dialogic teaching features, except the purposeful feature, which was demonstrated only by three teachers. Reciprocal and supportive features of dialogic teaching were the most difficult to demonstrate in the classroom, and the purposeful feature was better demonstrated. Physics teachers' CK of physics topics (Newtons' law of motion and graphical representation of motion) was limited. Even though the level of misconception varies, every teacher has misconceptions. Some teachers' misconceptions were severe, and they were not able to teach at this level. Teachers' content knowledge and training in dialogic teaching can promote the implementation of dialogic teaching.

\section{RECOMMENDATION}

My recommendations are:

1. In the teacher education program, it is better to choose a concurrent model of teacher education which uses both content and pedagogy training simultaneously rather than the consecutive model which focuses on the "how" of teaching, not the "what" to teach Aklilu, at al. (2008).

2. Caution must be taken in choosing participants from teacher in-service, as they seem to reluctant to respond urgently and participate in the research study.

\section{IMPLICATIONS}

In contrast to Education policy (MoE, 1994), and curriculum framework for Education (MoE, 2009), the study results show that due to the absence of dialogic teaching and limited teachers' CK:

- Most teachers were authoritative.

- Most classes were teacher-centered.

- Some teachers lead their students to misconceptions.

- Some teachers focus on quantitative than qualitative features of the topics and teach students beyond their level.

These indicated a gap between the intention of the policy and the actual happening in the school.

Most teachers from nine participants appeared to be limited in their CK of Newton's law of motion and graphical representation of motion. Even though their goals are indicated in grades 7 and 8, the physics syllabus, some teachers disregard the goals.

In teacher education and professional development programs, middle school physics contents should be incorporated; the pedagogy courses should focus on how to transform this content knowledge into teachable knowledge. Therefore, it is the responsibility of teacher training institutions (universities and colleges) and teacher training and development departments to develop concrete teacher education and development activities to enhance teacher's knowledge domains concerning physics contents they are intended to teach.

One of the possible reasons for the confusion/misconception of middle school physics teachers was textbooks. The textbooks did not demonstrate well the necessary steps in the graphical representation of motion. Therefore, the Ethiopian curriculum development department (General Education Department) needs to update the educational materials to be informative and sequential.

\section{REFERENCES}

Aklilu, D., Alemayehu, T-M., \& Mekasha, K. (2008). The structure and content of secondary school teacher education programs: international and national experiences. Journal of Education for Development, 2(2), 1-57.

Alemu, M., Kind, P., Tadesse, M., Atnafu, M., \& Michael, K. (2017). Challenges of science teacher education in low-income nations-The case Ethiopia. Part 13: Strand 13, 1782.

Alexander, R. (2006). Towards dialogic teaching. York: Dialogos.

Alexander, R. J. (2008). Towards dialogic teaching: Rethinking classroom talk. Dialogos York. 
Bakhtin, M. (1981). The dialogic imagination, trans. Caryl Emerson and Michael Holquist (Austin: University of Texas Press, 1981), 69.

Ball, D. L. (1989). Teaching mathematics for understanding: What do teachers need to know about the subject matter?. National Center for Research in Teacher Education.

Barbara, B., Alain, M., \& Ramahatra, R. (2003). Achieving universal primary education by 2015: A chance for every child. The World.

Brown, D. E. (1989). Students' concept of force: the importance of understanding Newton's third law. Physics Education, 24(6), 353. https://doi.org/ 10.1088/0031-9120/24/6/007

Clement, J. (1982). Students' preconceptions in introductory mechanics. American Journal of Physics, 50(1), 66-71. https:/ / doi.org/10.1119/1.12989

Crowell, B. (2001). Newtonian physics (Vol. 1): Light and Matter.

Crowell, B. (2003). Conservation laws (Vol. 2): Light and Matter.

Deakin Crick, R., Coates, M., Taylor, M., \& Ritchie, S. (2004). A systematic review of the impact of citizenship education on the provision of schooling, Research Evidence in Education Library (REEL) (London, EPPI-Centre, Social Science Research Unit, Institute of Education).

Fadaei, A. S., \& Moran, C. (2015). An investigation about misconceptions in force and motion in high school. US-china education review, 5(1), 38-45. https: / / doi.org/10.17265/2161-623X/2015.01.004

Forrester, P. A., \& Chinnappan, M. (2010). The predominance of procedural knowledge in fractions, 185-192. Retrieved from https:/ / ro.uow.edu.au/edupapers/770

Gillies, R. M. (2016). Dialogic interactions in the cooperative classroom. International Journal of Educational Research, 76, 178-189. https:/ / doi.org/10.1016/j.ijer.2015.02.009

Groth, R. E., \& Bergner, J. A. (2006). Preservice elementary teachers' conceptual and procedural knowledge of mean, median, and mode. Mathematical Thinking and Learning, 8(1), 37-63. https:/ / doi.org/10.1207/s15327833mt10801_3

Guerriero, S. (2015). Teachers' pedagogical knowledge and the teaching profession: Background report and project objectives. Better Policies for Better Lives, 1-7.

Halloun, I. A., \& Hestenes, D. (1985). The initial knowledge state of college physics students. American Journal of Physics, 53(11), 1043-1055. https://doi.org/10.1119/1.14030
Hestenes, D., Wells, M., \& Swackhamer, G. (1992). Force concept inventory. The physics teacher, 30(3), 141158. https:/ / doi.org/10.1119/1.2343497

Kumpulainen, K., \& Rajala, A. (2017). Dialogic teaching and students' discursive identity negotiation in the learning of science. Learning and Instruction, 48, 2331.

https:/ / doi.org/10.1016/j.learninstruc.2016.05.002

Lark, A. C. (2007). Student misconceptions in Newtonian mechanics. (Doctoral dissertation, Bowling Green State University).

Lyle, S. (2008). Dialogic teaching: Discussing theoretical contexts and reviewing evidence from classroom practice. Language and education, 22(3), 222-240. https:/ / doi.org/10.1080/09500780802152499

MacMillan, J., \& Schumacher, S. (2006). Research in education-Evidence-based Inquiry . International Edition: Boston: Pearson Education Inc. Pergamous Press.

Ministry of Education (MoE) (1994). Education and training policy. Addis Ababa Ethiopia: Ministry of Education.

Ministry of Education (MoE) (2002). The education and training policy and its implementation. Addis Ababa Ethiopia: Ministry of Education.

Ministry of Education (MoE) (2009). Curriculum Framework for Ethiopian Education (KG-Grade 12). Addis Ababa Ethiopia: Ministry of Education.

Poutot, G., \& Blandin, B. (2015). Exploration of Students' Misconceptions in Mechanics using the FCI. American Journal of Educational Research, 3(2), 116120. https:/ / doi.org/10.12691/education-3-2-2

Rayner, P., \& Ashcroft, K. (2011). Ethiopian higher education: Expansion, dilemmas and quality. World education news and reviews, 1 .

Reznitskaya, A. (2012). Dialogic teaching: Rethinking language use during literature discussions. The reading teacher. 65(7), 446-456. https://doi.org/ 10.1002/TRTR.01066

Semela, T. (2010). Who Is Joining Physics and Why? Factors Influencing the Choice of Physics among Ethiopian University Students. International Journal of Environmental and Science Education, 5(3), 319-340.

Serway, R., Faughn, J., \& Vuille, Chris (2008). College Physics. Cengage Learning.

Shulman, L. (1986). Those who understand: Knowledge growth in teaching. Educational researcher, 15(2), 414. https:/ / doi.org/10.3102/0013189X015002004

Talbert, J. E. (1993). Understanding Context Effects on Secondary School Teaching. Teachers College Record. 95(1), 45-68.

Tchoshanov, M., Lesser, L. M., and Salazar, J. (2008). Teacher knowledge and student achievement: Revealing patterns. NCSM Journal, 38, 39-49 
Thijs, G. D. (1992). Evaluation of an introductory course on" force" considering students' preconceptions. Science Education, 76(2), 155-74. https://doi.org/ 10.1002 /sce.3730760205

Thornton, R. K., \& Sokoloff, D. R. (1998). Assessing student learning of Newton's laws: The force and motion conceptual evaluation and the evaluation of active learning laboratory and lecture curricula. American Journal of physics, 66(4), 338-352. https://doi.org/10.1119/1.18863
Ugwuadu, O. (2013). Effects of democratic and authoritative discourse patterns on students' achievement in biology in mubi educational zone of adamawa state. IOSR Journal of Research $\mathcal{E}$ Method in Education, 2(3), 18-23. https://doi.org/10.9790/ 7388-0231823

Woldetsadik, G. (2013). National Learning Assessment in Ethiopia: sharing experiences and lessons. HD Learning Week. AFTEE, The World Bank.

http://www.ejmste.com 